\title{
Neuromuscular Disorders in Critically-Ill Patients - Approaches to Electrophysiologic Changes in Critical Illness Neuropathy and Myopathy
}

\author{
Fariba Eslamian and Mohammad Rahbar
}

Additional information is available at the end of the chapter

http://dx.doi.org/10.5772/50543

\section{Introduction}

Neurologic causes of profound weakness in an ICU (Intensive Care Unit) patient include disorders of the central nervous system (CNS) and the peripheral nervous system (PNS). Some of these are primary neurologic disorders that result in admission to the ICU, whereas others occur while the patient experiences prolonged hospitalization for unrelated medical problems.

These numerous non neurologic medical causes mainly including ischemic or hemorrhagic strokes, respiratory failure followed by COPD (chronic obstructive pulmonary disease) and asthma, acute or chronic renal failure, complications of ischemic heart diseases such as myocardial infarction and consequences of malignant processes. Most of these patients undergo mechanical ventilation, some of whom would subsequently be affected by neuromuscular disorders.

From the point of view of electroneurophysiology, these disorders are divided into three categories: 1) Critical Illness Neuropathy (CIN), 2) Critical Illness Myopathy (CIM), and 3) Prolonged Neuromuscular Junction Blockage [1].

In the present chapter, all of three above mentioned disorders as well as two axonal variants of Guillain-Barré Syndrome (GBS), namely Acute Motor Axonal Neuropathy (AMAN) and Acute Motor and Sensory Axonal Neuropathy (AMSAN) will be discussed in detail, which have differential diagnostic importance in distinguishing the etiology of weakness in critically-ill patients. Furthermore, we would have a glimpse into our experience derived from 14 hospitalized patients with prominent clinical picture of profound weakness, studying and comparing their neuromuscular disorders as clinical, electrodiagnostic, underlying diseases and incidence rate aspects, individually. 


\section{Clinical presentation}

Major clinical manifestation of these disorders includes a progressive weakness of the upper and lower extremities or all four limbs as quadriplegia or paraplegia along with hyporeflexia, hypotonia, with or without atrophy and weakness of the respiratory muscles.

The most common scenario commence with ICU hospitalization of the patients due to serious non-neurological medical reasons including above-mentioned etiologies (renal failure, COPD exacerbation, cerebral and gastrointestinal hemorrhage etc.). Majority of these patients are dependent on the ventilator and require neuromuscular junction blocking agents (NMBAs). During the recovery phase, the focus is on tapering sedatives and NMBAs which could be associated with occurrence of flaccid weakness in the upper and lower extremities and respiratory muscles; this in turns would delay weaning process from the ventilator [2]. On the other hand, patient status is likely to deteriorate toward sepsis or multi-organ failure and becoming ventilator-dependent for a long time. Performing electrodiagnostic tests to detect neuromuscular disorders delaying extubation is, hence, highly-indicated at this stage.

\subsection{Electrodiagnostic studies in ICU patients, technical issues}

Although electrodiagnostic (EDX) studies are mainly performed in outpatient setting, the number of the EDX studies in inpatient setting or hospitalized patients in ICU has recently been increased [2]. There is a number of challenging technical issues unique to performing EDX studies in the ICU and complicated ill patients. Some are related to patient factors, whereas others involve central and intravenous lines and electrical equipment that interfere with the performance of the study.

As previously mentioned, in these cases patients are profoundly ill, often with several serious overlapping medical problems. Most are intubated and receiving mechanical ventilation, which prevents them from traveling to the EMG laboratory, necessitating a portable study. But portable EDX device has its own problems such as interference with other electrical devices attached to the patient in ICU, noise and artifact production and increasing the potential risk of an electrical injury for sensitive patients.

These patients are often poorly cooperative and heavily sedated or agitated, who would not be able to roll on the sides or maintain positions required for performing the sensory or motor electrodiagnostic tests. Neither the agitated patient nor the sedated patient is able to give the electromyographer proper feedback during the study, for example, whether he or she is feeling the stimulus during the nerve conduction studies. Nor can such patients place their limbs in the correct position for the nerve conduction studies or the spontaneous activity assessment portion of the needle examination. Finally, they cannot cooperate with the examiner to activate their muscles voluntarily when trying to assess motor unit action potentials (MUAPs) during the needle examination [2]. 


\section{Our study patients}

Fourteen hospitalized patients from the Pulmonology ICU, Neurology and Internal Medicine wards with primary or secondary progressive weakness of the upper and lower limbs with or without respiratory muscles involvement were referred to the electrodiagnostic center, Physical Medicine and Rehabilitation department, Imam Reza Hospital, Tabriz, Iran in a one and half year period from August 2010 to February 2012.

In order to evaluate neuromuscular disorders and to diagnose the causes of weakness electro-neurophysiologically, Nerve Conduction Study and Needle Electromyography (NCS-EMG) were performed in all of referred patients. The data related to these patients including age, sex, admission reason, underlying diseases, past medical history, final diagnosis ,treatments and outcome are presented in Table-1.

A total of 14 patients were selected and examined. Based on NCS-EMG studies, patients were diagnosed as CIN in 4, CIM in 3, neuromyopathic critical illness in 4; including two patients with a combination of CIM and CIN and other two patients with previous acute or chronic neuropathy and superimposed subsequent CIM, AMAN in 2 and AMSAN only in one patient. We would briefly discuss about clinical and electrodiagnostic principals, techniques and features each of these entities in the next sections.

\section{Critical Illness Neuropathy (CIN)}

CIN or CIP (Critical Illness Polyneuropathy) is reported as the most common severe neuropathy in ICU patients, mostly observed in patients hospitalized due to primary nonneurological medical problems. The main reason for its occurrence is a reactive systemic inflammatory response to sepsis or trauma [2]. Unlike GBS, CIN is an axonal polyneuropathy and considered whenever there are signs of fixed weakness in the extremities, sensory loss or inability to wean from the ventilator despite beginning clinical improvement of the patient.

Although CIN has been reported to be more frequent than CIM in several studies [3], in a study with 88 patients, the incidence ratio of CIM was reported to be three times more than CIN (42\% vs. 13\%). The results of this study showed that among patients who underwent EMG in ICU population, acute myopathy is three times as common as acute axonal polyneuropathy, and the outcomes from acute myopathy and acute axonal polyneuropathy may be similar [4]. In other words, mortality and morbidity are comparable in both of them.

In addition to polyneuropathy, mononeuropathies including unilateral or bilateral phrenic neuropathy are frequently seen in CIN, which contribute to respiratory disorders requiring EDX for accurate diagnosis [2].

\subsection{Electrophysiologic features in CIN}

Although, as above mentioned, EDX is associated with difficulties in ill and complicated patients, based on previous studies as well as present study results, electrodiagnostic findings could be summarized as the following: 
Compound muscle action potentials (CMAPs) are profoundly reduced in amplitude or absent. Motor conduction velocities are normal or slightly reduced and distal latencies are normal or slightly prolonged, while sensory nerve action potentials (SNAPs) should be significantly diminished in amplitude or unobtainable. Phrenic nerve study also reveals absence or reduction of obtained CMAP from diaphragm muscle, which will be explained in the end of this section.

In pure $\mathrm{CIN}$, neurogenic pattern including high amplitude and polyphasic motor unit action potentials (MUAPs) with reduced recruitment are observed in needle electromyography [5]. However, patients are sometimes unable to perform motor units recruitment and nothing could be detected due to patients' poor effort. In these situations, the only observable sign in the needle EMG would be presence of denervation potentials (fib/psw) at the rest phase of needle exam.

Electrodiagnostic criteria of the present study were based on these principals and all of above-mentioned characteristics were applied to our patients diagnosed with CIN as well.

Some points should be highlighted regarding the EDX findings in CIN: firstly, if SNAPs were normal or mildly low amplitude associated with diminished CMAPs, other diagnosis rather than CIN would be investigated i.e. CIM (critical illness myopathy) or AMAN (motor axonal neuropathy). At this point, needle EMG differentiates these two entities from each other. Secondly, another fact to be kept in mind is that low amplitude SNAPs could be related to previous underlying disease such as diabetes or renal failure and subsequent diabetic or uremic neuropathy rather than CIN. Thirdly, in cases with mixed CIN and CIM, in spite of the fact that SNAPs are abnormal, myogenic pattern in needle EMG demonstrates muscle weakness may be more related to the superimposed myopathy.

\subsection{Phrenic nerve electrodiagnostic study}

One of the major reasons contributing to unsuccessful weaning trials from the ventilator in intubated patients is unilateral or bilateral phrenic neuropathy which could be idiopathic, due to autoimmune or post-infection etiologies such as Bell's palsy and secondary to iatrogenic causes after coronary artery bypass grafting or other thoracic surgeries [2].

Phrenic nerve could also be affected as an accompanying disorder observed with polyneuropathies such as GBS or CIN. To obtain phrenic nerve CMAP, recording electrode is secured a few centimeters proximal to the xyphoid process while the reference electrode being placed $16 \mathrm{~cm}$ lower along with the ribcage on both sides corresponding to the phrenic nerve excited. Stimulation electrode is placed $3 \mathrm{~cm}$ superior to the clavicle parallel to the cricoid cartilage [6]. The important issue is that normal amplitude for phrenic CMAP is 300$500 \mu \mathrm{v}$ which in fact could be associated with unclear responses due to the electrical noise existing in the ICU. 


\begin{tabular}{|c|c|c|c|c|c|c|c|}
\hline $\begin{array}{l}\text { No. of } \\
\text { Patients }\end{array}$ & Age & $\operatorname{sex}$ & $\begin{array}{l}\text { The cause of } \\
\text { admission }\end{array}$ & $\begin{array}{l}\text { Underlying } \\
\text { disease }\end{array}$ & Past Medical History & $\begin{array}{l}\text { Progress of disease and } \\
\text { outcome }\end{array}$ & \begin{tabular}{|c|} 
Electrodiagno \\
stic \\
Impression
\end{tabular} \\
\hline$\# 1$ & 64 & $\mathrm{M}$ & Respiratory failure & gastric cancer & $\begin{array}{l}\text { Surgery of total } \\
\text { Gastrectomy, } \\
\text { IHD,Asthma }\end{array}$ & $\begin{array}{c}\text { Mechanical ventilation, } \\
\text { worsening of general status } \\
\text {,expire }\end{array}$ & $\mathrm{CIN}^{\mathrm{a}}$ \\
\hline$\# 2$ & 63 & $\mathrm{~F}$ & Acute pancreatitis & - & $x_{1}$ & $\begin{array}{c}\text { Treatment of pancreatitis } \\
\text { and recovery }\end{array}$ & $\mathrm{CIN}$ \\
\hline$\# 3$ & 36 & $\mathrm{M}$ & $\begin{array}{c}\begin{array}{c}\text { Acute Respiratory } \\
\text { distress Syndrome } \\
\text { (ARDS) }\end{array} \\
\end{array}$ & $\begin{array}{l}\text { Methadone } \\
\text { poisoning }\end{array}$ & Addiction & $\begin{array}{c}\text { GI bleeding, hypoxic } \\
\text { Encephalopathy+ Intubation }\end{array}$ & $\mathrm{CIN}$ \\
\hline$\# 4$ & 66 & $\mathrm{M}$ & $\begin{array}{c}\text { Acute renal failure } \\
\text { (ARF) }\end{array}$ & $\begin{array}{c}\text { ATN }^{\mathrm{b}} \text { secondary } \\
\text { to over dosage } \\
\text { of NSAIDs }\end{array}$ & $\begin{array}{l}\text { NSAIDs intake } \\
\text { because of } \\
\text { musculoskeletal } \\
\text { problems }\end{array}$ & $\begin{array}{c}\text { Treatment of Pneumonia, } \\
\text { Hemodialysis for ARF, } \\
\text { recovery }\end{array}$ & $\mathrm{CIN}$ \\
\hline$\# 5$ & 15 & F & $\begin{array}{l}\text { Rectal bleeding } \\
\text { and } \\
\text { unconsciousness }\end{array}$ & Seliac disease & $\begin{array}{c}\text { Surgery of } \\
\text { Appendectomy }\end{array}$ & $\begin{array}{l}\text { Bowel obstruction, } \\
\text { respiratory disturbance } \\
\text { +intubation }\end{array}$ & $\mathrm{CIM}^{\mathrm{C}}$ \\
\hline$\# 6$ & 37 & M & $\begin{array}{l}\text { Dyspenea } \\
\text { exacerbation }\end{array}$ & corpulmonale & $\begin{array}{c}\text { Kyphoscoliosis in } \\
\text { thoracic and lumbar } \\
\text { spinal area }\end{array}$ & $\begin{array}{l}\text { Mechanical ventilation + } \\
\text { tracheostomy, partial } \\
\text { recovery }\end{array}$ & CIM \\
\hline$\# 7$ & 54 & F & $\begin{array}{c}\text { Intra ventricular } \\
\text { hemorrhage (IVH) }\end{array}$ & $\begin{array}{l}\mathrm{ICH}^{\mathrm{d}}, \mathrm{IVH} \text { and } \\
\text { hydrocephaly }\end{array}$ & Hypertension & $\begin{array}{c}\text { Intubation+ prolonged } \\
\text { Mechanical ventilation, } \\
\text { expire }\end{array}$ & CIM \\
\hline$\# 8$ & 66 & M & $\begin{array}{c}\text { Dyspenea } \\
\text { exacerbation }\end{array}$ & $\mathrm{COPD}^{\mathrm{e}}$ & $\begin{array}{l}\text { COPD, Diabetes, } \\
\text { hypertension }\end{array}$ & $\begin{array}{l}\text { Intubation+ prolonged } \\
\text { Mechanical ventilation }\end{array}$ & $\mathrm{CIN} / \mathrm{CIM}^{\mathrm{f}}$ \\
\hline$\# 9$ & 25 & M & quadriparesia & $\begin{array}{l}\text { Traumatic SCI } \\
\text { in C5-C6 levels }\end{array}$ & - & $\begin{array}{l}\text { Prominent LMNg signs } \\
\text { (Lower and upper limbs } \\
\text { weakness, hypotonia and } \\
\text { hyporeflexia),excess of } \\
\text { UMN }^{\mathrm{h}} \text { signs related to SCI }\end{array}$ & CIN/CIM \\
\hline$\# 10$ & 55 & $\mathrm{M}$ & $\begin{array}{c}\text { Progressive lower } \\
\text { limbs weakness }\end{array}$ & LBP & $\begin{array}{l}\text { History of LBP, } \\
\text { radiculopathy, } \\
\text { epidural injections }\end{array}$ & $\begin{array}{l}\text { Treatment for neuropathy } \\
\text { and CIM, partial recovery }\end{array}$ & \begin{tabular}{|c|} 
CIM super- \\
imposed on \\
chronic \\
sensorimotor \\
polyneuro- \\
pathy
\end{tabular} \\
\hline$\# 11$ & 42 & F & $\begin{array}{c}\text { Progressive lower } \\
\text { and upper limbs } \\
\text { weakness }\end{array}$ & $\begin{array}{c}\text { FUO (fever with } \\
\text { unknown } \\
\text { origin) }\end{array}$ & $\begin{array}{l}\text { First admission } 40 \\
\text { days before second } \\
\text { admission, because } \\
\text { of FUO and then } \\
\text { treatment for GBS }\end{array}$ & $\begin{array}{c}\text { Treatment for tuberculosis } \\
\text { meningitis , treatment for } \\
\text { following AMAN and CIM, } \\
\text { partial recovery with } \\
\text { persistent paraparesia } \\
\end{array}$ & $\begin{array}{c}\text { CIM, } \\
\text { superimpose } \\
\text { d on AMANI }\end{array}$ \\
\hline$\# 12$ & 44 & F & $\begin{array}{c}\text { Progressive lower } \\
\text { limbs weakness }\end{array}$ & $\begin{array}{l}\text { Lumbar } \\
\text { radiculopathy }\end{array}$ & $\begin{array}{c}\text { LBP and history of } \\
\text { lumbar disc surgery } \\
\text { three months ago. }\end{array}$ & $\begin{array}{c}\text { Complicated with } \\
\text { pulmonary thrombo emboli } \\
\text { (PTE), phrenic nerve } \\
\text { neuropathy }\end{array}$ & AMAN \\
\hline$\# 13$ & 72 & M & $\begin{array}{c}\text { Progressive lower } \\
\text { limbs weakness }\end{array}$ & $\begin{array}{l}\text { Upper } \\
\text { respiratory } \\
\text { infection } \\
\end{array}$ & $\begin{array}{c}\text { Weakness started } \\
\text { one week after } \\
\text { respiratory infection }\end{array}$ & $\begin{array}{l}\text { Treatment for AMAN with } \\
\text { IVIG and recovery }\end{array}$ & AMAN \\
\hline$\# 14$ & 60 & M & $\begin{array}{l}\text { Exacerbation of } \\
\text { COPD }\end{array}$ & COPD & COPD & $\begin{array}{l}2 \text { weeks after admission } \\
\text { lower limbs weakness was } \\
\text { occurred, treatment for } \\
\text { COPD and following } \\
\text { AMSAN }\end{array}$ & AMSAN \\
\hline
\end{tabular}

${ }^{a}$ Critical illness neuropathy ${ }^{b}$ Acute tubular necrosis ${ }^{\mathrm{c}}$ Critical illness myopathy ${ }^{\mathrm{d}}$ Intracranial hemorrhage ${ }^{\mathrm{e}} \mathrm{Chronic}$ obstructive pulmonary disease ${ }^{\mathrm{f}}$ combined critical illness neuropathy and myopathy (neuromyopathic syndrome) sLower motor neuron ${ }^{\mathrm{h}} \mathrm{Upper}$ motor neuron ${ }^{\mathrm{I}}$ Acute motor axonal neuropathy ${ }^{\mathrm{T} A c u t e}$ motor and sensory axonal neuropathy

Table 1. Characteristics of ill patients with profound weakness, who were referred for electrodiagnosis 
Needle EMG of the diaphragm muscle is performed in cases with phrenic nerve involvement accompanying CIN as well as CIM. For this purpose, needle is inserted between the two Anterior Axillary and Medial clavicular lines, through $7^{\text {th }}$ or $8^{\text {th }}$ intercostal spaces, exactly over the rib. Neurogenic or myogenic patterns with or without fib/psw could be detected in inspiration phase of respiration [6].

Phrenic nerve EDX was requested for 4 of 14 patients in the present study. In two patients diagnosed with CIN and mixed neuromyopathic syndrome, there was no phrenic nerve involvement. In one patient secondary to AMAN, phrenic neuropathy was detected as bilateral asymmetric low amplitude CMAPs associated with neurogenic pattern in the diaphragm muscle and in one patient secondary to CIM, phrenic nerve involvement was revealed as bilateral absent CMAPs along with fib/psw and myogenic pattern in diaphragm muscle.

It should however be borne in mind that phrenic nerve EDX is mostly helpful whenever bilateral normal or unilateral abnormal responses are detected. In other words, if responses would be absent bilaterally it is difficult to distinguish from technical reasons [2].

Treatment: There is no specific treatment for CIN and supportive measures should be taken to avoid multi organ failure occurrence.

\section{Critical Illness Myopathy (CIM)}

The most common muscular disorder leading to weakness in ICU is critical illness myopathy. CIM is also known as acute quadriplegic myopathy, thick filament myopathy and ICU myopathy [1,2].

CIM is mostly seen concomitant to the administration of intravenous steroids and NMBAs; this complication is frequent in patients with asthma, COPD and administration of highdose intravenous methyl-prednisolone [1].

Occurrence of one case of CIM and one case of mixed CIM/CIN in our patients' series with the history of hospitalization due to COPD exacerbation or corpulmonale confirms this fact (Table 1). This disorder however could also be seen in critically ill patients with sepsis or multiorgan failure without history of receiving corticosteroids or NMBAs. Prolonged mechanical ventilation per se even with absence of mentioned medications usage could cause CIM as well. In some cases, CIM is associated with increase in serum CPK levels (up to 10 times the upper limit of normal) [1]. High mortality rates with CIM; even a rate of $30 \%$ have been reported [4]. Of course, it should be noticed that the mortality cause has mostly been due to the sepsis or multiorgan failure rather than the myopathy itself. In present study, one case with pure CIM and one case with CIN were expired (Table 1). Survived and treated patients would acquire ambulation ability within the following 3-4 months [1].

From the histopathologic aspect, type II muscle fiber atrophy is observed more frequently than type I. In muscle biopsy, specific signs of myosin loss is often detected which solely could not explain the inexcitability of the muscle membrane that occurs with this myopathy. 
Therefore, the following three factors contributing to reduction in muscle membrane excitability are introduced [7]:

1. Partial depolarization of the resting membrane potential,

2. Reduced membrane resistance,

3. Decreased sodium currents

Furthermore, released cytokines throughout sepsis could be associated with a catabolic state in muscles and results in breakdown of structural proteins $[1,7]$.

\section{Electrophysiologic features in CIM}

Nerve conduction studies demonstrate diminished amplitudes of CMAPs with normal distal latencies and conduction velocities. In contrast, SNAPs are normal or mildly reduced (greater than $80 \%$ of lower limit of normal) [1]. Repetitive stimulation test (RST) is usually normal, but in some studies decreasing response after high rate and low rate RST have also been reported [8].

Electromyography frequently demonstrates prominent fibrillation potentials and positive sharp waves (fib/psw), which is rarely accompanied by myotoinc discharges. Short duration, small -amplitude and polyphasic MUAPs that recruit early are evident. In severe cases, it may be difficult to recruit and activate any MUAPs [1]. Of course, this process is reversed and small MUAPs will be appeared again during the recovery period.

\subsection{Direct muscle stimulation technique}

Direct muscle stimulation technique is utilized for differentiation CIM from critical illness neuropathy. This method has been reported by Rich and colleagues for first time [7, 9]. In fact, direct muscle stimulation bypasses distal motor nerve and neuromuscular junction area. This technique is performed by placing a monopolar needle stimulating electrode as cathode in the distal third of muscle using $0.1 \mathrm{msec}$ stimulus duration with gradually increasing current from 10 to $100 \mathrm{~mA}$ until a clear twitch is seen. A subdermal needle electrode as active recording electrode is placed $1-3 \mathrm{~cm}$ from the stimulation electrode. The stimulation intensity is increased until a maximal response or direct muscle action potential (dm CMAP) is obtained. Next, using the same recording montage, nerve to the muscle is stimulated in the usual manner to obtain a nerve- evoked compound muscle action potential (ne CMAP) [2]. As a result muscle membrane should retain its excitability, direct muscle stimulation CMAP (dm CMAP) should be near normal despite a low or absent nerve stimulation evoked CMAP (ne CMAP). In contrast, if the muscle membrane excitability is reduced, both the ne CMAP and dm CMAP should be very low [1]. Therefore, in CIM as well as normal people, the ne CMAP/ dm CMAP ratio is close to one (1:1), because both amplitudes is proportionally reduced or normal, respectively. In CIN or neuromuscular junction disorder, the ratio is much lower and approaches zero because of disproportionally lower ne CMAP compared with the dm CMAP.

In conclusion, absent or low amplitude of dm CMAP with ne CMAP/ dm CMAP greater than 0.9 is demonstrated in majority of patients with CIM, While ne CMAP/ dm CMAP ratio is 0.5 or less in patients with severe CIN [1]. 


\subsection{Treatment}

There is no medical therapy other than supportive care and treating underlying systemic abnormalities (e.g., antibiotics in sepsis). If patients are still receiving high doses of corticosteroids or non- depolarizing neuromuscular blockers, the medications should be stopped.

\section{Critical illness neuropathy in combination with myopathy (Neuromyopathic syndrome)}

Patients occasionally present with combination of CIN and CIM symptoms, which make it complicated to distinguish or detect from each other [1].This condition is named as Neuromyopathic Syndrome.

In our patients' series, Neuromyopathic Syndrome was observed in 4 from 14 patients, two of whom had a combination of CIN and CIM. Third case admitted with chronic severe motor and sensory neuropathy symptoms; later presence of myogenic pattern in needle EMG revealed additional CIM. Forth patient suffered from FUO (Fever unknown origin) and demonstrated CIM which had been superimposed on previously diagnosed AMAN. (Table1). One explanation is partly related to this fact, that preexisting neuropathic aspects in these patients were completed parallel to disease progression and subsequently myogenic process and thick filament myopathy initiated following intubation and administration of NMBAs and corticosteroids. We categorized these cases in "Neuromyopathic Syndrome" or "combination of critical illness neuropathy and myopathy" group.

\subsection{Electrophysiologic features in combined CIN/CIM}

NCS shows CMAPs and SNAPs both are low amplitude or unobtainable. NCVs are reduced but within axonal range (greater than $60-70 \%$ of lower limit of normal). Despite of these neuropathic features, myogenic process with low amplitude, short duration and polyphasic MUAPs are mostly seen, which is occasionally associated with patchy neurogenic changes in needle electromyography examination.

Table 2 illustrates the electrodiagnostic changes in differential diagnosis among critically ill patients.

\begin{tabular}{|c|c|c|c|c|c|c|}
\hline & $\begin{array}{l}\text { Low amplitude } \\
\text { or absent SNAP }\end{array}$ & $\begin{array}{l}\text { Low amplitude } \\
\text { or absent CMAP }\end{array}$ & $\begin{array}{c}\text { Reduced NCV }> \\
60-70 \% \\
\text { of LLNa }\end{array}$ & fib/psw ${ }^{b}$ & $\begin{array}{l}\text { Myogenic } \\
\text { Pattern }\end{array}$ & $\begin{array}{c}\text { Neurogenic } \\
\text { Pattern }\end{array}$ \\
\hline $\mathrm{CIN}^{\mathrm{c}}$ & ++ & ++ & - & ++ & - & ++ \\
\hline CIM $^{\mathrm{d}}$ & - & ++ & - & +++ & ++ & - \\
\hline GBSe & $+/-$ & $+/-$ & ++ & - & - & + \\
\hline AMAN $^{f}$ & - & + & - & ++ & - & ++ \\
\hline AMSANg & + & + & - & + & - & + \\
\hline CIN/CIM ${ }^{\mathrm{h}}$ & + & + & - & ++ & + & $+/-$ \\
\hline
\end{tabular}

aLower Limit of Normal, bFibrillation Potentials, cCritical Illness Neuropathy, dCritical Illness Myopathy, eGullian Barre Syndrome, ${ }^{\mathrm{f}}$ Acute Motor Axonal Neuropathy, ${ }^{\mathrm{g}}$ Acute Motor and Sensory Axonal Neuropathy, hcombination of CIN and CIM (Neuromyopathic syndrome)

Table 2. Electrodiagnostic changes in various neuromuscular disorders among critically ill patients 


\section{Prolonged Neuromuscular Junction Blockage:}

Neuromuscular junction block (NMJ block) occurs primarily in diseases like Myastenia gravis and Lambert-Eaton myastenic syndrome without simultaneous myopathy or neuropathy. However, this complication is frequently observed in association with CIN or CIM in critically ill patients who secondarily affected by neuromuscular disorders.

The definite diagnosis is achieved by performing RST or RNS (Repetitive Nerve Stimulation Test) and appearance of decreasing responses and fatigue following repetitive stimulation of low rates at 2-3 Hz in Myastenia gravis or NMJ block in combination with CIM. In contrast, increment responses and facilitation are observed following stimulation of high rates at 25$50 \mathrm{~Hz}$ in Lambert-Eaton syndrome [10].

It should be mentioned that pure NMJ block are rarely seen in these patients. In the present study, RST was not performed to confirm the simultaneous NMJ block for referred patients, who were critically ill and poorly cooperative with definite diagnosis in each category of CIN, CIM, AMAN, etc., because of this fact that RST tests are time consuming, painful and somewhat unnecessary, since it does not add extra benefit concerning the final therapeutic process as well as prognosis in this spectrum of patients.

In the previous sections, approaches to critically ill patients suspected of having neuropathy or myopathy were reviewed, now we turn our focus to the other neuropathies, which are in the differential diagnostic list of profound weakness in the inpatient or ICU setting. These disorders are often amenable to treat, so correct diagnosis is important.

\section{Acute inflammatory demylinating polyradiculoneuropathy (AIDP)}

The most well known acute neuropathy that results in marked weakness and respiratory compromise is Guillain-Barre syndrome (GBS) [2]. GBS is an acquired motor and sensory polyradiculneuopathy that is usually demylinating.

\subsection{Electrophysiologic features in GBS}

Demylinating is prescribed with motor nerve conduction velocity less than $60-70 \%$ of LLN (lower limit of normal), prolonged distal motor latencies and F-waves greater than $25-50 \%$ of ULN( upper limit of normal), absent F-waves and presence of conduction block or temporal dispersion in one or more motor nerves in electrodiagnostic studies. These criteria have been defined and reported by Cornblath et al, and are used as research criteria for diagnosis of GBS since 1990 [11,12].

In our patients' series, there was no case of GBS and as previously mentioned most of them were hospitalized due to primary non-neurologic medical reasons and CIN or CIM was added later. Other cases that were presented with weakness in upper and lower extremities with or without other medical problems were included in axonal variants of GBS, which is discussed as follows. 


\section{Acute motor and sensory axonal neuropathy (AMSAN)}

Feasby and colleagues initially reported this axonal variant of GBS in 1986 [13]. Clinical and electrodiagnostic features in AMSAN are indistinguishable from those with AIDP initially [5]. Patients with AMSAN refer with a rapidly progressive and generalized weakness which progresses within days unlike the AIDP which progresses within weeks. Ophthalmoparesia, swallowing disorders, and facial muscles weakness are prominent in these patients. Other accompanying symptoms include complete areflexia, sensory loss and autonomic disorders such as arrhythmia. Most of these patients would require ventilator and their prognosis are often poorer compared with AIDP patients.

\subsection{Electrophysiologic features in AMSAN}

NCS reveal markedly diminished amplitudes or absent CMAPs. SNAPs are also profoundly low amplitude or absent. But distal latencies of CMAPs and NCVs, when obtainable, should be normal or only mildly affected [5] .In other words, this abnormality would be within axonal range(greater than $60-70 \%$ of LLN). Neurogenic pattern with large MUAPs with or without denervation potentials are seen in needle EMG exam (Table 2).

In the present study, there was one case with AMSAN had started with above-mentioned clinical picture followed by COPD exacerbation and diagnosis was confirmed by EDX criteria.

\subsection{Treatment}

Because it is difficult to distinguish AIDP from AMSAN clinically or electrophysiologically, at least initially, treatment with plasma exchange or IVIG is warranted [5].

\section{Acute Motor Axonal Neuropathy (AMAN)}

In northern china, AMAN is the most common variant of GBS [14].Clinical manifestation is similar to that of AMSAN and GBS, however distal muscles are affected more severely than proximal muscles. Respiratory failure and mechanical ventilation requirement is observed in one third of the patients. Unlike AMSAN and GBS no sensory sings are noted. Furthermore, Anti-GM1 antibody for Compilobacter jejuni is more frequently detected in patients with AMAN especially in Children [15].

\subsection{Electrophysiologic features in AMAN}

Low amplitude or absent CMAPs with normal SNAPs and mildly reduced NCVs, are the characteristic features of nerve conduction studies in AMAN. Other EDx evidences are similar to AMSAN as above noted.

In our patients' series, there were two cases with AMAN from whom one case was associated with phrenic nerve involvement and diaphragm muscle paralysis with 
respiratory disturbances. There was also a case without respiratory involvement with an appropriate response to IVIG (Table 1).

\subsection{Treatment}

It is suggested to treat AMAN patients with IVIG $2 \mathrm{mg} / \mathrm{kg}$ over 5 days or plasma exchange as an alternative. One of large studies reported no significant difference in outcome regardless of therapy (IVIG,PE,..) between AIDP and AMAN among 300 patients[15].

In conclusion, CIN and CIM have no cure, so in this conditions, underlying disease and drugs dose should be treated and adjusted, respectively; despite of this management, muscle power weakness lasts several months to recover. AIDP, AMAN and AMSAN, however, are curable and therefore distinguish them together is important.

\section{Author details}

Fariba Eslamian and Mohammad Rahbar

Tabriz University of Medical Sciences, Physical medicine E Rehabilitation Research Center, Tabriz, Iran

\section{References}

[1] Dumitru D, Amato AA (2002) Acquired myopathies. In: Dumitru D, Amato AA, Zwarts MJ, editors. Electrodiagnostic medicine. 2nd ed. Philadelphia, PA: Hanley \& Belfus Inc; pp. 1402-1404.

[2] Preston DC, Shapiro BE (2005) Approach to Electrodiagnostic Studies in the Intensive Care Unit. In: Preston DC, Shapiro BE, eds. Electromyography and Neuromuscular disorders. 2nd ed. Philadelphia, Elsevier. pp.615-625

[3] Op de Coul AAW, Lambregts PC, Koeman J,et al (1985) Neuromuscular complications in patients given Pavulon during artificial ventilation. Clin Neurol Neurosurg . 87:17-20.

[4] Lacomis D, Petrella JT, Giuliani MJ (1998) Causes of neuromuscular weakness in the intensive care unit: a study of ninety-two patients. Muscle Nerve. 21(5):610-7

[5] Dumitru D, Amato AA (2002) Acquired neuropathies In: Dumitru D, Amato AA, Zwarts MJ, editors. Electrodiagnostic medicine. 2nd ed. Philadelphia, PA: Hanley \& Belfus Inc; pp.937-989.

[6] Dumitru D, Zwarts MJ (2002) Focal cranial neuropathies. In: Dumitru D, Amato AA, Zwarts MJ, editors. Electrodiagnostic medicine. 2nd ed. Philadelphia, PA: Hanley \& Belfus Inc; pp.688-690.

[7] Rich MM, Teener JW, Raps EC, Schotland DL, Bird SJ (1996) Muscle is electrically unexcitable in acute quadriplegic myopathy. Neurology. 46(3):731-6

[8] Road J, Mackie G, Jiang TX, Stewart H, Eisen A (1997) Reversible paralysis with status asthmaticus, steroids, and pancuronium: clinical electrophysiological correlates. Muscle Nerve. 20(12):1587-90 
[9] Rich MM, Bird SJ, Raps EC, McCluskey LF, Teener JW (1997) Direct muscle stimulation in acute quadriplegic myopathy. Muscle Nerve. 20(6):665-673.

[10] Dumitru D, Amato AA (2002) Neuromuscular junction disorders. In: Dumitru D, Amato AA, Zwarts MJ, eds. Electrodiagnostic medicine. 2nd ed. Philadelphia, PA: Hanley \& Belfus Inc. pp.1148-1177.

[11] Cornblath DR, Asbury AK, Albers JW (1991) Research criteria for diagnosis of chronic inflammatory demyelinating polyneuropathy (CIDP). Neurology. 41:617-618.

[12] Cornblath DR, Mellits ED, Griffin JW, McKhann GM, Albers JW, Miller RG, Feasby TE, Quaskey SA (1988) Motor conduction studies in Guillain-Barré syndrome: description and prognostic value. Ann Neurol. 23(4):354-359.

[13] Feasby TE, Gilbert JJ, Brown WF, Bolton CF, Hahn AF, Koopman WF, Zochodne DW (1986) An acute axonal form of Guillain-Barré polyneuropathy. Brain. 109 (Pt 6):11151126.

[14] McKhann GM, Cornblath DR, Ho T, Li CY, Bai AY, Wu HS, Yei QF, Zhang WC, Zhaori $11 \mathrm{Z}$, Jiang Z, et al. (1991) Clinical and electrophysiological aspects of acute paralytic disease of children and young adults in northern China. Lancet. 7; 338(8767):593-597.

[15] Hadden RD, Cornblath DR, Hughes RA, Zielasek J, Hartung HP, Toyka KV, Swan AV (1998) Electrophysiological classification of Guillain-Barré syndrome: clinical associations and outcome. Plasma Exchange/Sandoglobulin Guillain-Barré Syndrome Trial Group. Ann Neurol. 44(5):780-788. 